\title{
PERANCANGAN DAN PEMBUATAN PEMBANGKIT LISTRIK TENAGA MIKROHIDRO PADA SALURAN SUNGAI OPAK UNTUK MENDUKUNG PEREKONOMIAN MASYARAKAT DUKUH BENDO, DESA WUKIRSARI, KECAMATAN IMOGIRI, KABUPATEN BANTUL, YOGYAKARTA
}

\author{
Slameto \\ JurusanTeknikKonversiEnergi -PoliteknikNegeri Bandung \\ Email slameto2264@yahoo.com
}

\begin{abstract}
Abstrak
Energi adalah kebutuhan yang vital untuk masyarakat, ketersediaan energi alternatif di Indonesia khususnya untuk mikrohidro sekitar $450 \mathrm{MW}$, sementara baru digunakan sekitar 84MW. Di provinsi Yogyakarta misalnya, masih sedikit penggunaan energy altenatif ini, padahal wilayah ini memiliki banyak potensi sumber mikrohidro. Studi ini merupakan studi ulang tahapan wal pembangunan PLTMH. Studi yang dilakukan yaitu berupa survey kelayakan, perancangan dan pembangunan PLTMH di dukuh Bendo, desaWukirsari, Bantul, Yogyakarta. Dari data yang didapatkan saluran irigasi ini mampu menghasilkan daya sekitar 714 Watt, dengan luasan 1,76m², Kecepatan $0,85 \mathrm{~m} / \mathrm{s}$ dan debit $1,5 \mathrm{~m}^{3} / \mathrm{s}$.
\end{abstract}

Kata kunci : Bendo, Wukirsari, PLTMH, Perancangan dan Pembuatan

\section{INTISARI}

Kincir air adalah merupakan sarana untuk merubah energi air menjadi energi mekanik yang berupa daya mekanik, torsi dan putaran pada poros kincir. Kopling adalah merupakan bagian dari sistem mikrohidro yang berfungsi untuk memindahkan atau mentransmisikan daya, putaran dan torsi dari poros kincir ke poros transmisi. Pada abad ke 19 penggunaan kincir air masih tetap dipakai sampai sekarang. Terutama pada daerah atau wilayah yang belum terjangkau listrik PLN atau pada industri yang keberadaannya didalam hutan seperti kebun teh, kebun karet dan lain sebagainya

Umumnya penggunaan kincir air hanya terbatas pada skala kecil atau sedang saja sedangkan untuk skala besar turbin airlah menjadi pilihan. Namun demikian kincir air memiliki kelebihan karena biayanya relatif murah, pembuatannya mudah dan yang lebih menarik lagi untuk pembangkit listrik pada aliran sungai dengan head sangat rendah penggerak mula yang paling tepat adalah model kincir.

Ada beberapa tipe kincir air yaitu :

1. Kincir Air Overshot

2. Kincir Air Undershot

3. Kincir Air Breastshot

4. Kincir Air Tub

Keberadaan suluran air di dusun Bendo yang tidak pernah surut sepanjang tahun sangat cocok untuk dibangun mikrohidro, yang dapat dimanfaatkan bagi masyarakat untuk mendukung perkembangan perekonomian masyarakat disekitarnya. Adapun kincir yang yang sesuai dengan kondisi saluran air dipilih tipe kincir air undershot

Dari seluruh rangkaian hasil perencanaan, pembuatan, pengujian dan kajian, maka dapat disimpulkan daya yang dihasilkan generator sinkron $3 \mathrm{~kW}$ adalah 310 Watt dengan tegangan 180 Volt sampai 230 Volt, dipergunakan penerangan jalan pada malam hari sebanyak 32 titik masing-masing 8 Watt sedangkan pada siang hari dipergunakan untuk pemecah/pletes kedelai sebagai bahan baku pembuat tempe. Dari analisa data dan kajian didapat effisiensi sebesar $43,8 \%$. Untuk menjaga dan mendukung pengoperasian mikrohidro ini diharapkan peran dan perhatian dari pemerintah daerah maupun pusat sangat dinantikan, agar dikemudian hari mikrohidro ini dapat berkembang dengan baik

\section{PENDAHULUAN}

Seiring dengan perkembangan peradaban manusia, tingkat kebutuhan energy semakin meningkat. Pemenuhan energy ini sebagian besar berasal dari energy fosil yang tidak dapat diperbaharui hanya sebagian kecil saja yang berasal dari energy terbarukan. Celakanya penggunaan bahan bakar fosil banyak menimbulkan masalah diantaranya masalah lingkungan, kesehatan, ekonomi, dll. Rasio elekrifikasi di Yogyakarta baru mencapai $84,48 \%$, dan seharusnya rasio ini ditinggkatkan 
menjadi $100 \%$. Dengan peningkatan rasio elektrifikasi ini membutuhkan adanya peningkatan bahan bakar. Hal ini akan meningkatan dampak negative. Sehingga perlu adanya konversi ke sebuah energi terbarukan seperti pembangkit listrik tenaga mikrohidro yang ramah lingkungan, murah dan mudah pembangunannya. Sehingga sudah sepantasnya usaha ini mendapat dukungan dari pemerintah.

\section{MAKSUD DAN TUJUAN}

Maksud dari studi ini adalah untuk mengoptimalkan potensi-potensi aliran air dari saluran irigasi sungai opak yang belum dimanfaatkan untuk PLTMH. Sedangkan tujuannya adalah untuk membantu kemajuan masyarakat dusun Bendo, Kelurahan Wukirsari, Imogiri, Bantul dengan memanfaatkan listrik untuk penerangan jalan pada malam hari dan untuk pletes kedelai bahan baku tempe pada siang hari serta pada musim kemarau dapat dipergunakan sebagai penggerak pompa untuk mengaliri sawah.

\section{DASAR TEORI}

\section{Hidrodinamika dan Hidrolika}

Hidrodinamika adalah ilmu yang mempelajari gerakan air dan gaya yang ditimbulkannya, sedangkan hidrolika adalah ilmu terapan dari hidrodinamika (Maryono dkk, 2003). Tiga persamaan dasar dalam hidrolika yaitu persamaan kontinuitas, energi dan momentum.

Persamaan kontinuitas:

$$
Q=A_{1} V_{1}=A_{2} V_{2}=\text { konstan }
$$

dengan: $\mathrm{Q}=$ debit aliran $\left(\mathrm{m}^{3} / \mathrm{s}\right), \mathrm{A}=$ luas tampang aliran $\left(\mathrm{m}^{2}\right), \mathrm{V}=$ kecepatan rerata aliran pada tampang tersebut $(\mathrm{m} / \mathrm{s})$, danIndeks 1 dan 2 adalah nomor tampang aliran air yang ditinjau.

Persamaan Bernoulli

$$
\mathrm{Z}_{1}+\frac{p_{1}}{\gamma}+\frac{V_{1}^{2}}{2 g}=\mathrm{Z}_{2}+\frac{p_{2}}{\gamma}+\frac{V_{2}^{2}}{2 g}
$$

dengan: $Z$ =elevasi tinggi tempat, $\frac{p}{\gamma}=$ head tekanan, $\frac{V^{2}}{2 g}=$ head kecepatan.

Persamaan momentum

$$
F=\rho Q\left(V_{2}-V_{1}\right)
$$

Dengan: $\mathrm{F}$ = gaya yang ditimbulkan oleh aliran zat cair $(\mathrm{N}), \rho=$ rapat massa aliran $\left(\mathrm{kg} / \mathrm{m}^{3}\right), \mathrm{Q}=$ debit aliran $\left(\mathrm{m}^{3} / \mathrm{s}\right), \mathrm{V}=$ kecepatan aliran $(\mathrm{m} / \mathrm{s})$

\section{Gaya Ditimbulkan oleh Aliran Zat Cair}

Jika suatu pancaran zat cair menghantam plat datar dengan luas tampang A, kecepatan aliran $\mathrm{V}$ dan rapat massa air $\rho$ maka pancaran air yang menghantam plat akan menyebar kesegala arah, dan kecepatan pancaran pada plat dalam arah horisontal adalah nol. Gaya yang ditimbulkan oleh pancaran air pada plat adalah R. Sebaliknya plat juga menimbulkan gaya $F$ yang bekerja pada zat cair, yang besarnya sama tetapi berlawanan arah dengan R. Untuk plat vertikal yang tetap, maka

$$
R=-F=\rho A V^{2}
$$

Untuk plat miring dengan sudut , maka $\mathrm{R}$ adalah

$$
R=-F=\rho A V^{2} \sin
$$

Jika plat miring bergerak dengan kecepatan v,

$$
R=-F=\rho A(V-v)_{(2) \operatorname{Sin}}^{2} \theta
$$

Untuk plat datar yang bergerak dengan kecepatan $\mathrm{v}$, maka menjadi

$$
R=-F=\rho A(V-v)^{2}
$$

Untuk plat datar yang dipasang di sekeliling roda, maka persamaan $\mathrm{R}$ adalah:

$$
R=-F=\rho A V(V-v)
$$

Sedangkan jika plat berbentuk lengkung, dengan $\alpha$ adalah sudut antara kecepatan pancaran yang menghantam plat dengan arah horisontal, $\beta$ adalah sudut antara kecepatan pancaran yang 
meninggalkan plat dengan arah horisontal, gaya yang ditimbulkan adalah:

Komponen gaya horisontal

$R_{x}=\rho A V(V \cos \alpha+V \cos \beta)$.

Jika $\alpha=\beta=0$, makaR $_{\mathrm{x}}=2 \rho \mathrm{A} \mathrm{V}^{2}$

Artinya gaya pada plat lengkung dimana pancaran membelok $180^{\circ}$ adalah dua kali gaya yang terjadi pada plat datar.

Komponen gaya vertikal, maka

$$
R=\rho A V(V \sin \alpha-V \sin \beta) .
$$

Jika $\alpha=\beta=0$, maka $\mathrm{R}_{\mathrm{y}}=0$

Jika plat lengkung bergerak dengan kecepatan $\mathrm{v}$ searah dengan pancaran $\mathrm{V}$, setelah menghantam plat pancaran meninggalkan plat dengan lintasan membentuk sudut $\beta$ terhadap horisontal, maka:

$$
R=-F=\rho A(V-v)^{2}(1+\operatorname{Cos} \beta)
$$

Apabila terdapat suatu seri plat lengkung yang dipasang pada poros roda, maka:

$$
R=-F=\rho A V(V-v)(1+\operatorname{Cos} \beta)
$$

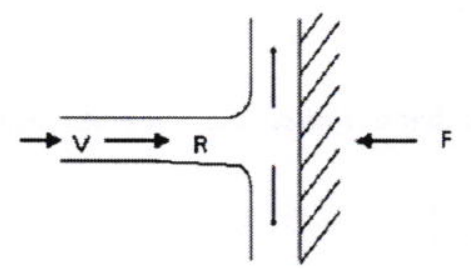

Gambar 1. Pancaran air pada plat datar

Dengan : $F=$ Gaya, $R=$ Resultan gaya, dan $V=$ Kecepatan fluida.

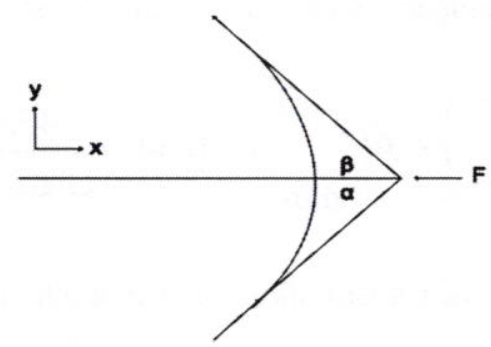

Gambar 2. Pancaran pada plat lengkung tetap

Dengan : $\quad F=$ Gaya, $\alpha=$ sudut masuk fluida, dan $\beta$ = sudut keluar fluida

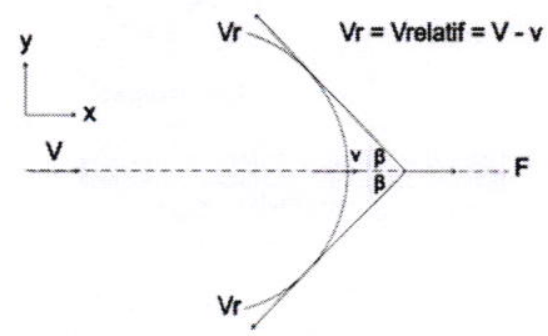

Gambar 3. Pancaran Searah Gerak Plat Lengkung

Dengan : $\quad \mathrm{F}=$ Gaya, $\mathrm{Vr}=$ kecepatan relatif fluida, $\beta$ = sudut masuk dan keluar fluida, $\mathrm{V}=$ kecepatan masuk fluida.

\section{Perancangan Kincir}

Dari gambaran diatas, didapatkanjeniskincir yang tepat adalah tipe undershot dengan spesifikasi sebagai berikut.

$$
\begin{array}{ll}
\text { - Diameter kincir }\left(\mathrm{D}_{1}\right) & =298 \mathrm{Cm} \\
\text { - } & =60 \mathrm{Cm} \\
\text { - Jumal Kincir } & =16 \mathrm{Bh} \\
\text { - Daya Terencana } & =714 \mathrm{Watt} \\
\text { - Daya Terbangkitkan } & =310 \mathrm{Watt} \\
\text { - Putaran Kincir } & =7 \mathrm{Rpm} \\
\text { - Pilo blok tipe } & =P 209 \mathrm{~N}
\end{array}
$$

\section{Perancangan Transmisi}

Transmisi roda gigi mempunyai beberapa keuntungan diantaranya dapat digunakan untuk mentransmisikan daya yang besar, digunakan untuk jarak sumbu poros yang kecil, mempunyai efisiensi yang tinggi, mempunyai bentuk yang kompak. Selain beberapa keuntungan diatas terdapat beberapa kekurangan diantaranya adalah membutuhkan manufaktur yang rumit sehingga mahal dibandingkan dengan transmisi lainnya, kesalahan dalam pemotongan gigi dapat menyebabkan getaran dan bunyi selama operasi, membutuhkan pelumasan yang baik. 


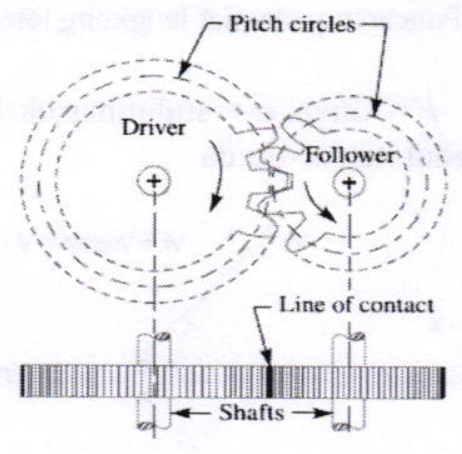

Gambar 4. Gear atau roda gigi

Transmisi rantai digunakan untuk meneruskan daya tanpa slip, sehingga dapat menjamin perbandingan putaran yang tetap. Selain itu juga terdapat beberapa keuntungan diantaranya mampu meneruskan daya besar, keausan kecil pada bantalan, mudah dalam pemasangannya, mempunyai efisiensi yang lebih tinggi sampai $98 \%$, dapat mentransmisikan daya yang lebih besar dari belt, mengijinkan perbandingan kecepatan 8 sampai 10 dalam satu tingkat. Sedangkan kelemahan dari system transmisi ini adalah harga relatif lebih tinggi dari belt, transmisi rantai membutuhkan perawatan yang lebih misalnya pelumasan.

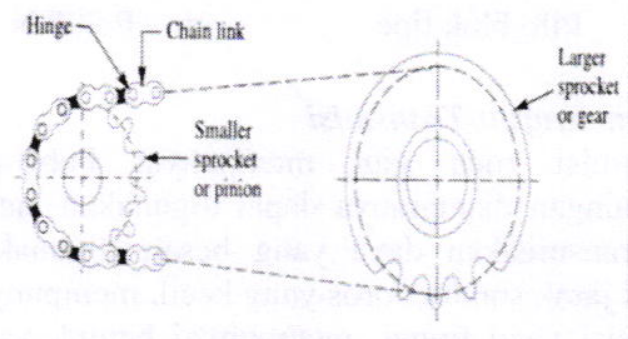

Gambar 5. Sproket dan rantai

Pulley dan Belt digunakan untuk mentransmisikan daya dari penggerak mula ke generator yang berputar pada kecepatan yang sama atau berbeda. Daya yang di transmisikan tergantung pada kecepatan belt, sudut kontak, tegangan, dll. Jika kecepatan belt meningkat, maka gaya sentrifugal akan meningkat yang mana akan menarik belt jauh dari pulley. Hal ini akanmenurunkan daya yang ditransmisikan.

Transmisi mekanik ini jauh lebih murah dari jenis Gearbox, tetapi tidak tahan lama. Efisiensinya berkisar antara $95 \%-98 \%$ (Khurmi dan Gupta, 2005). Untuk melakukan perhitungan rasio kecepatan digunakan persamaan, panjang dari sabuk driver per menit sama dengan panjang dari driven per menit, dirumuskan sebagai berikut:

$$
\begin{aligned}
\pi d_{1} N_{1} & =\pi d_{2} N_{2}, \text { atau } \frac{N_{2}}{N_{1}}=\frac{d_{1}}{d_{2}} \\
\frac{N_{4}}{N_{1}} & =\frac{d_{1} \times d_{3}}{d_{2} \times d_{4}}
\end{aligned}
$$

Dengan memperhitungkan slip yang terjadi antara pulley dan belt maka persamaan diatas menjadi:

$$
\frac{N_{4}}{N_{1}}=\frac{d_{1} \times d_{3}}{d_{2} \times d_{4}} \times\left(1-s_{1} \%\right) \times\left(1-s_{2} \%\right)
$$
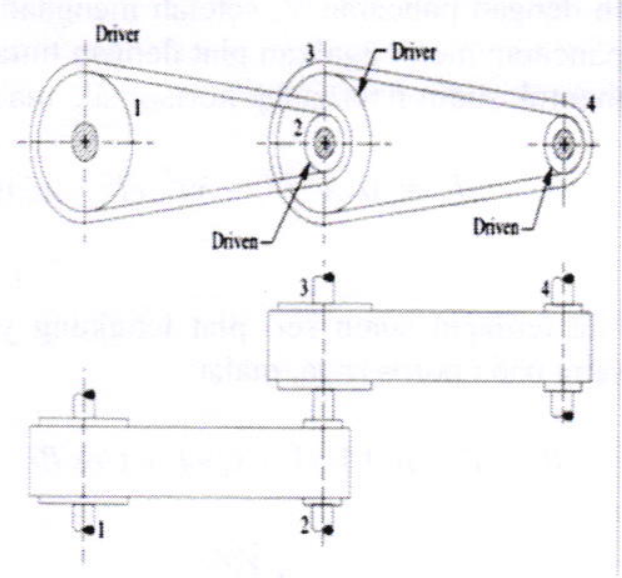

Gambar 6. Pulley dan belt bertingkat

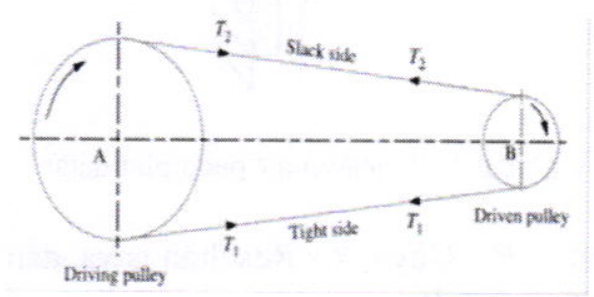

Gambar 7. Gaya padapulleydanbelt

$2,3 \log \left(\frac{T_{1}}{T_{2}}\right)=\mu \theta \quad \mu=0,54-\frac{42,6}{152,6+v}$

Daya yang di transmisikan oleh belt adalah:

$$
P=\left(T_{1}-T_{2}\right) v
$$


Dimana $\mathrm{T} 1=$ gaya pada sisi ketat $(\mathrm{N}), \mathrm{T} 2=$ gaya pada sisi kendor $(\mathrm{N}), \theta=$ sudut kontak (rad), $\nu=$ kecepatan belt $(\mathrm{m} / \mathrm{s}), \mu=$ koefisien, $\mathrm{s} 1 \%=$ slip pada tingkat pertama, $\mathrm{s} 1 \%=$ slip pada tingkat kedua. Panjang belt dapat ditentukan dengan persamaan seperti gambar dibawah ini

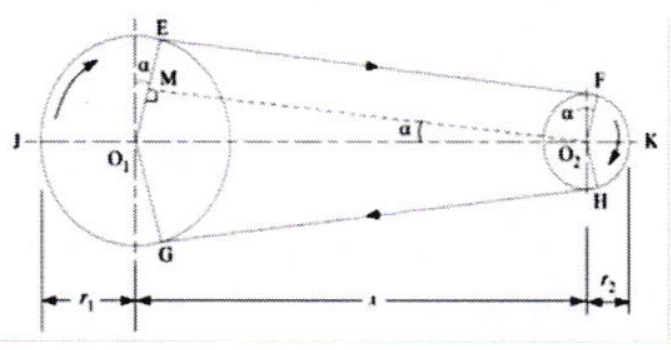

Gambar 8. Dimensi Pully dan Belt

$$
L=\pi\left(r_{1}+r_{2}\right)+2 x+\frac{\left(r_{1}-r_{2}\right)^{2}}{x}
$$
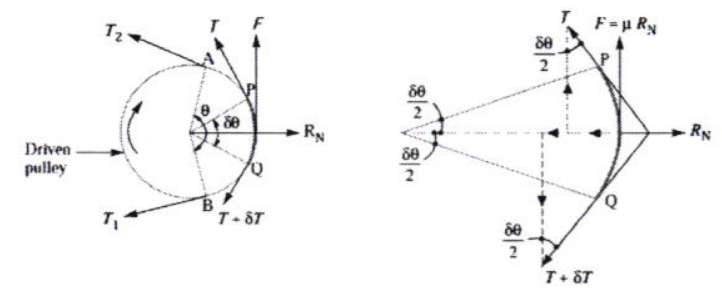

Gambar 9. Perbandingan rasio gaya pada belt

$\theta=\left(180^{\circ}-2 \alpha\right) \frac{\pi}{180} \mathrm{rad} \operatorname{dan} \sin \alpha=\frac{r_{1}-r_{2}}{x}$

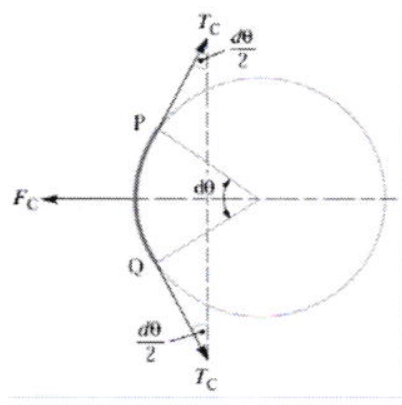

Gambar 10. Gaya sentrifugal

Gaya sentifugal yang bekerja pada belt PQ

$$
F_{c}=m \cdot r \cdot d \theta \times \frac{v^{2}}{r}=m \cdot d \theta \cdot v^{2}
$$

\section{a. Perancangan generator}

Kapasitas dari generator sinkron yang dihasilkan sebesar 310 Watt, generator 4 kutub, putaran $1450 \mathrm{rpm}$ dengan tegangan keluaran $220-230 \mathrm{~V}, \cos \phi=0,9$ dan frekuensi output 50 Hz. Karena putarankincir sebesar $7 \mathrm{rpm}$ maka perbandingan transmisi sebesar $207 \mathrm{Rpm}$

\section{b. Analisis ekonomi}

Untuk menentukan kelayakan pembangunan PLTMH di perlukan suatu evaluasi secara ekonomi yaitu :NPV ( Net Present Value )

$$
N P V=\sum_{i=1}^{n} \frac{R_{i}-\left(I_{i}+O_{i}+M_{i}\right)+V_{r}}{(1+r)^{i}}
$$

Dengan $: \mathrm{Ri}=$ pendapatan, $\mathrm{Ii}=$ investasi, $\mathrm{Oi}=$ biaya operasi, $\mathrm{Mi}=$ Biaya pemeliharaan, $\mathrm{Vr}=$ nilai residu, $\mathrm{r}=$ discount rate, $\mathrm{n}=$ jumlah tahun Jika nilai NPV bernilai positif berarti bahwa pembangunan itu layak dilanjutkan.

\section{SISTEM PEMANFAATAN}

Dalam sistem ini PLTMH tidak hanya berfungsi sebagai alat untuk menghasilkan listrik saja, namun bisa dipakai untuk berbagai fungsi yang lain. Seperti pompa air, pembubutan dan pemotong kayu, mesin penggiling padi, beras, pletes kedelai dan lain-lain

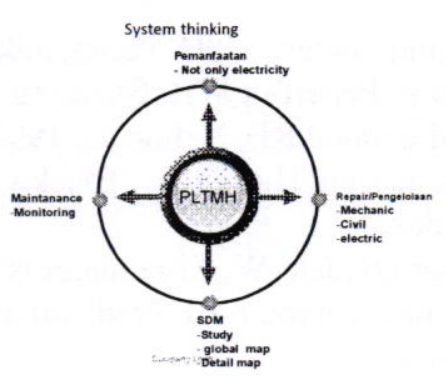

Gambar 11. Pola Pikir Sistem

\section{HASIL PERANCANGAN}

Dari data hasil perancangan didapatkan hasil sebagai berikut :

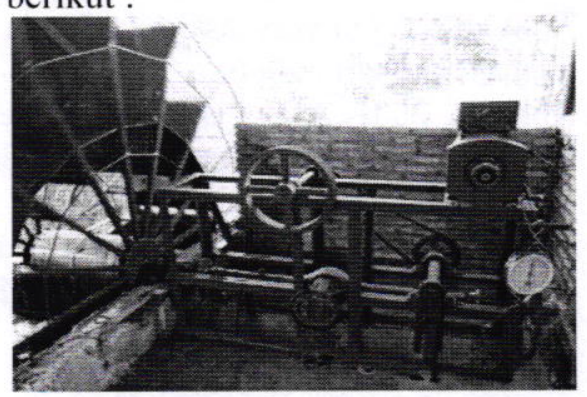


Gambar 12. PLTMh Kincir Air

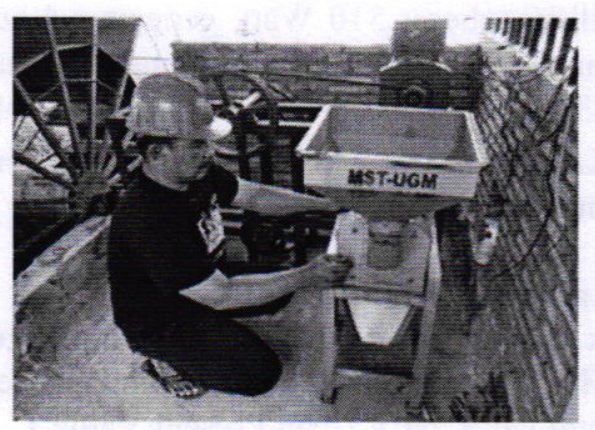

Gambar 13. PLTMh Sebagai Penggerak Mesin Pemecah/Pletes Kedelai

Tabel 1: Hasil perancangan PLTMH

\begin{tabular}{|l|c|}
\hline \multicolumn{1}{|c|}{ Parameter } & Jumlah \\
\hline Daya listrik yang dihasilkan (Watt) & 310 \\
\hline Debit ( Q ) $\mathrm{m}^{3} / \mathrm{s}$ & 1,5 \\
\hline Diameter kincir (Cm) & 298 \\
\hline Lebar kincir (Cm) & 60 \\
\hline Putaran kincir (rpm) & 7 \\
\hline Putaran Generator (rpm) & 1450 \\
\hline Kapasitas generator (kW) & 3 \\
\hline Beban terpasang @ 8 Watt & 32 \\
\hline Penggerak Mesin Pletes kedelai (set) & 1 \\
\hline Penggerak Mesin parut kelapa (set) & 1 \\
\hline Penggerak Mesin pompa air (set) & 1 \\
\hline NPV ( Net Present Value ) & positif \\
\hline
\end{tabular}

\section{DAFTAR PUSTAKA}

[1]. Arismunandar, 2004. Penggerak Mula Turbin. Penertbit ITB, Bandung.

[2]. Featherstone RE, Nalluri C, 1995. Civil Engeneering Hidraulics. Blackwell Science. London

[3]. Maryono ,dan W, Eisenhauer N. 2003. Hirolika Terapan. PT PradnyaParamita, Jakarta

[4]. Maryono, 2011. Pola Pikir Sistem. edisi I. Magister Sistem Teknik FT-UGM. Yogyakarta.

[5]. Majesty, H. 2004. Micro-Hydropower System. Natural Resources Canada

[6]. Sucipto W. 2009. Desain Pengembangan dan Peningkatan Efisiensi Kincir Ismun. Tesis. MST, UniversitasGadjahMada

[7]. SantosadanAdji , 2006

[8]. Khurmi, 2001. A Tex Book Machine Design. Chand and Company. LTD. Ram Nagar. New Delhi.

[9]. Sularso. Suga Kiyokatsu. 2008. Dasar Perencanaan dan Pemilihan Elmen Mesin. Pradnya Paramita. Jakarta.
[10]. Ismun. 2008. Presentasi Pembangkit

Listrik Tenaga Mikrohidro. UGM.

Yoyakarta.

[11]. Zoe Jones, 2005, 